\title{
FORMAÇÃO DOCENTE PARA A PRODUÇÃO DE MATERIAL PARA A EDUCAÇÃO DIGITAL
}

\author{
Katia Ethiénne Esteves dos Santos \\ Raquel Pasternak Glitz Kowalski \\ Sueli Perazzoli Trindade
}

Resumo

Esta pesquisa tem como objetivo refletir sobre a formação de docentes envolvidos com a produção de materiais para a educação digital, que envolve, tanto a educação em todo tempo e lugar em contextos não formais, como a Educação a Distância e a Educação Híbrida. Nesta reflexão o foco é para a educação híbrida/semipresencial que se entende ter um papel relevante na inserção de tecnologias e na mudança de paradigmas na graduação e pós-graduação, impulsionando a formação de professores para que atuem de forma mais efetiva inserindo as tecnologias em seu cotidiano educacional, torna-se relevante. Este estudo de caráter qualitativo contou com um questionário estruturado que investigou professores autores e desenvolvedores na produção de material didático para educação híbrida. Os pontos abordados na investigação foram a formação docente, o planejamento das disciplinas híbridas, as metodologias ativas com o uso das tecnologias e autorreflexão sobre os conhecimentos docentes para essa modalidade. Percebe-se que a formação continuada é cada vez mais relevante quando o contexto inclui a educação híbrida por seu caráter inovador e transformador.

Palavras-chave: educação digital; educação híbrida; formação docente.

\section{T'EACHER EDUCATION FOR PRODUCTION OF DIGITAL} EDUCATION MATERIAL

Abstract

This research aims to reflect on the education of teachers involved in the production of materials for digital education, which involves both education at all times and in non-formal contexts, such as Distance Education and Hybrid Education. In this reflection the focus is on hybrid / semi-presential education, which is considered to have a relevant role in the insertion of technologies and in the change of paradigms in undergraduate and postgraduate programs, promoting the formation of teachers to act more effectively by inserting technologies in your educational daily life. This qualitative study had a structured questionnaire that investigated teachers who are authors and developers in the production of didactic material for hybrid education. The points addressed in the investigation were teaching education, the planning of hybrid subjects, the active methodologies with the use of technologies and self-reflection on teaching knowledge for this modality. Continuing education is becoming increasingly relevant when the context includes hybrid education for its innovative and transformative character.

Keywords: hybrid education; digital education; teacher education.

\section{FORMACIÓN DOCENTE PARA LA PRODUCCIÓN DE MATERIAL} PARA LA EDUCACIÓN DIGITAL

Resumen

Esta investigación tiene como objetivo reflexionar sobre la formación de los docentes involucrados en la producción de materiales para la educación digital, que implica la educación en todo momento y en contextos no formales, así como la Educación y la Educación Híbrida. En esta reflexión, la atención se centra en la educación híbrida / semipresencial, que se considera que tiene un papel relevante en la inserción de tecnologías y en el cambio de paradigmas en los estudios de pregrado y posgrado, fomentando la formación de docentes para que actúen de manera más efectiva mediante la inserción de tecnologías en su vida educativa diaria, se vuelve relevante. Este estudio de carácter cualitativo ha sido elaborado con un 
cuestionario estructurado que investigó profesores autores y desarrolladores en la producción de material didáctico para la educación híbrida. Los puntos abordados en la investigación fueron la formación del profesorado, la planificación de asignaturas híbridas, las metodologías activas con el uso de tecnologías y la autorreflexión sobre los conocimientos docentes para esta modalidad. Se nota que la educación continua es cada vez más relevante cuando el contexto incluye la educación híbrida por su carácter innovador y transformador.

Palabras clave: educación híbrida; educación digital; formación docente.

\section{INTRODUÇÃO}

A educação digital tem tomado um espaço cada vez mais efetivo no cotidiano das pessoas, portanto envolve inúmeras habilidades e conhecimentos que independem do conhecimento que os indivíduos têm sobre as diferentes tecnologias e dispositivos digitais. As possibilidades que a educação digital tende a preparar os cidadãos capazes de conviver no mundo e compreender riscos, desafios e oportunidades.

Entende-se a amplitude deste momento histórico, como cita Santos (2018, p. 33) “[...] é relevante ressaltar que a educação digital em alguns documentos é considerada a capacidade de ter "educação nos ambientes on-line e ser ético", complementada pelo conceito apresentado por Monteiro e Moreira (2012, s. p.) "[...] um processo que se caracteriza pela conectividade, rapidez, fluidez e utilização de recursos abertos, mas que é necessário, pois, desencadeia processos educativos destinados a melhorar a qualidade dos processos pedagógicos".

A educação digital tende a oferecer espaços para moldar comportamentos, para a superação de desafios, para a construção de uma sociedade melhor, valorizando o papel de cada um com responsabilidade e ética, o que transforma o pensar sobre as demandas deste século, tão inusitado.

As reflexões do pesquisador Preti (2011, p. 18) apresentam elementos referentes a amplitude desta questão:

Quando, pois, estamos falando de Educação, estamos nos referindo a todos os aspectos da vida que ela abarca nas relações pessoais, sociais, políticas, com a natureza, como entorno. Ela está imiscuída, misturada e diluída em tudo. É parte do todo, é o todo. Portanto, não haveria necessidade de adjetivá-la, de apontar este ou aquele aspecto particular. Corre-se o risco de enfocar em demasia o secundário e abafar sua fonte, a origem de sua parturição, de seu nascimento.

A educação digital com características mais flexíveis, personalizadas, onlife (o tempo todo e em todo lugar) tende a suprir um novo paradigma, resultante de transformações sociais, e que visa a mudança de estruturas, com a inserção de práticas didático-pedagógicas-tecnológicas inovadoras nas propostas educacionais e com a ressignificação das questões de tempo e espaço.

Percebe-se que a crescente internacionalização de recursos humanos, financeiros e de desenvolvimento, oportunizam o escalonamento da mobilidade de estudantes e de professores, além de ampliar a realização dos processos de ensino e de aprendizagem, a produção de materiais e de tecnologias educacionais a serem utilizadas em diferentes espaços.

Este processo de reconstrução dos espaços, virtuais e presenciais, impulsionam também alterações técnicas e metodológicas, numa perspectiva de diálogo, entre a formação de professores e a educação híbrida.

Nesta perspectiva reflexiva observar a questão da formação continuada dos professores impulsiona a existência de redes de (auto) formação, como cita Nóvoa (1995, p. 26), que “[...] permitam compreender a globalidade do sujeito, assumindo a formação como processo interativo 
e dinâmico", além de terem como premissa a inserção de tecnologias nos ambientes educacionais, formais e não formais.

\section{FORMAÇÃO DOCENTE}

Com o avanço tecnológico em todas as áreas profissionais na atual sociedade, o ser humano necessita de uma formação que integre os vários saberes para interpretar o contexto profissional e pessoal. Nesse sentido, a teoria da complexidade na educação contribui na ressignificação dos saberes por meio da contextualização.

Na concepção de Morin (2011, p. 13), o importante é criar possibilidades que viabilizem as práticas pedagógicas com um "[...] pensamento complexo, ecologizado, capaz de relacionar, contextualizar e religar diferentes saberes ou dimensões da vida". A humanidade precisa de mentes mais abertas, escutas mais sensíveis, pessoas responsáveis e comprometidas com a transformação de si e do mundo.

Para repensar e ressignificar a educação, pautada na complexidade presente em toda a realidade, necessitamos da compreensão sobre a teia de relações existentes entre sujeito e objeto. O sentido do pensar a educação está na teoria e na prática, de que tudo se liga a tudo, e no aprender a aprender que professor e estudante transcendem para além das áreas do conhecimento.

Nos processos do ensino e aprendizagem com as metodologias ativas se faz necessária uma reflexão pedagógica que contextualize o conhecimento, no qual estudante e professor são protagonistas do processo de ensino e sujeitos do conhecimento ao construir os saberes articulados no saber ser, fazer, conviver e aprender.

Com as transformações sociais, científicas e tecnológicas no contexto histórico, social e cultural, novas reflexões e discussões surgem na educação com o objetivo de atender de forma efetiva as necessidades desta nova sociedade contemporânea, pois uma de suas vertentes é o desenvolvimento tecnológico.

De acordo com Candau e Moreira (2007, p.19), é “[...] necessário repensar e reescrever o currículo nos processos do ensino e da aprendizagem de forma contextualizada e articulada, proporcionando ao estudante uma visão de mundo conectada às mais diversas particularidades do conhecimento".

Historicamente, as políticas educacionais têm se preocupado com a formação docente, a partir das exigências na formação humana por meio de competências, habilidades e atitudes que possibilitam o ser humano estar apto a assumir e desenvolver sua profissão com criatividade, coerência, coesão e capacidades tecnológicas.

Considerando que o percurso formativo no ensino e aprendizagem possibilita a interação do estudante na sociedade por meio das experiências de vida com as tecnologias, requer um professor que seja capaz de adotar, adaptar e transformar as questões pessoais, sociais, profissionais por meio da conscientização, harmonia e trabalho coletivo com vistas para uma aprendizagem significativa a partir de contribuições das metodologias ativas e modelos híbridos.

$\mathrm{Na}$ concepção dos autores Bacich e Moran (2018, p.12), “[...] a combinação de vários espaços, tempos, atividades, metodologias, públicos formando uma educação híbrida, misturada e mesclada sempre esteve presente no contexto educacional".

No contexto atual da educação, as discussões enfatizam contribuições e interligações das metodologias ativas no contexto híbrido, ou seja, inverter a sala de aula por meio das práticas pedagógicas proporciona a contextualização dos saberes ontológico, epistemológico e 
metodológico na construção do conhecimento científico. Além disso, ampliar a percepção, compreensão e argumentações pertinentes na formação docente.

Para Severino (2002), precisamos de educadores que ensinem o estudante a pensar, ou seja, criar estratégias que possibilitem o gosto de pensar, de aprender de dialogar, consequentemente, o estudante pode se reconhecer como sujeito de ideias, de palavras, como uma pessoa que tem o que dizer e que pode dizer, e que será ouvida, porque tem argumentos relevantes ao contextualizar os diferentes saberes.

O professor pesquisador com uma visão aberta às inovações tecnológicas na educação, se propõe a buscar práticas pedagógicas com vistas para a aprendizagem ativa e significativa, consegue criar um ambiente colaborativo com avanços nos níveis de aprendizagem, ou seja, na perspectiva da forma espiral.

Entende-se que o estudante constrói o conhecimento a partir do nível simples para o mais complexo, assim, desenvolve as competências e habilidades em todas as dimensões da vida.

São caminhos que cruzam e se entrecruzam formando uma teia com saberes em diversas áreas de conhecimento, a qual se transforma em aprendizagem ativa e significativa na formação docente, consequentemente, refletida na sala de aula com os estudantes. Por conseguinte, Bacich e Moran (2018, p. 182) afirmam:

No processo de ensinar e aprender, é fundamental que a construção de sentido seja entrelaçada a construção dos significados. O sentido, o proposito e o objetivo do aprender, para cada um, devem se entrelaçar com os significados socialmente construídos do conhecimento acumulado nas ciências, na cultura e na tecnologia.

Nas metodologias ativas e na educação híbrida professor e estudante são aprendentes no processo de aprender e ensinar, ambos são protagonistas do conhecimento. E juntos ampliam o repertório de conhecimento ao conectar-se com o mundo que habitamos por meio de redes virtuais ou contato presencial. Para Almeida e Valente (2012), a configuração dos papéis do professor e do estudante nas metodologias ativas de aprendizagem associadas às tecnologias digitais proporciona a reflexão sobre as teorias e práticas pedagógicas.

Tendo em vista que o ser humano aprende por meio de diversas formas: técnicas, procedimentos, estratégias, trilhas, métodos, práticas e experiências e a aprendizagem ativa possibilita a flexibilidade cognitiva que se refere à capacidade de superar a fragmentação, reducionismo que aprisiona o conhecimento, a formação docente deve oportunizar as condições necessárias e fundamentais para enfrentar os desafios no contexto educacional.

Nos processos de ensino e aprendizagem as metodologias como diretrizes orientam o percurso formativo, no qual se transformam em estratégias, abordagens e técnicas que concretizam a construção do conhecimento. Sendo assim, compreendemos que as metodologias ativas são constituídas de estratégias de ensino pertinentes no ambiente escolar, no qual a participação do estudante é efetiva de forma flexível, interativa e hibrida.

Neste contexto, Bacich e Moran (2018, p. 4):

As metodologias ativas, num mundo conectado e digital, expressam-se por meio de modelos de ensino híbridos, com muitas possíveis combinações. A junção de metodologias ativas com modelos híbridos traz contribuições importantes para o desenho de soluções atuais para os aprendizes de hoje.

Neste cenário da aprendizagem significativa, o papel do professor é de orientador e tutor dos estudantes nas atividades individuais e em grupo. Segundo Bacich e Moran (2018, p.130), tornar o professor proficiente no uso das tecnologias digitais de forma integrada ao currículo é 
importante para uma abordagem que se traduza em melhores resultados na aprendizagem dos estudantes.

O comprometimento com a realização e qualidade da aprendizagem está na forma de organizar as trilhas que proporcionam ao estudante o sentido de estudar determinado conteúdo, isto é, provocar inquietações que o motivem a buscar mais conhecimento sobre o objeto de estudo e que contextualize com a sua vida e com as dinâmicas da sociedade.

Corrobora nesta reflexão sobre a importância da formação dos professores para atuar nos processos de ensino e aprendizagem quanto ao despertar no estudante o gosto, o apreço pelo aprender, os autores Bacich e Moran (2018, p. 6):

A personalização é um processo complexo, que exige maturidade e autonomia crescente dos estudantes e também docente muito bem preparado e autonomia crescente dos estudantes muito bem preparados e renumerados, bom apoio institucional e infraestrutura tecnológica. Os professores precisam descobrir quais são as motivações profundas de cada estudante, o que os mobiliza a aprender, os percursos, técnicas e tecnologias mais adequadas para cada situação e combinar atividades individuais e grupais e on-line.

Ser docente hoje é transcender o espaço limitado da sala de aula e contemplar as dimensões que compõem o mundo, a vida, o ser humano, sobretudo, agregando os múltiplos saberes que constituem a base da prática profissional do docente. Conforme Bacich e Moran (2018, p.09), “[...] o papel ativo do professor como designer de caminhos, de atividades individuais e em grupo é decisivo e diferente. O professor torna-se, cada vez mais, um gestor e orientador de caminhos coletivos e individuais".

Entende-se que as metodologias ativas na formação docente auxiliam na elaboração e organização do currículo em projetos contemplando o ensino com pesquisa e a integração dos meios digitais na interconexão entre teoria e prática; espaço e tempo; a comunicação pessoal e colaborativa; presencial e online.

Para Freire (1996, p. 32):

Não há ensino sem pesquisa e pesquisa sem ensino. Esses que fazeres se encontram um no corpo do outro. Enquanto ensino contínuo buscando, reprocurando. Ensino porque busco, porque indaguei, porque indago e me educo. Pesquiso para conhecer o que ainda não conheço e comunicar ou anunciar a novidade.

O ambiente escolar pode ser um espaço propício para as discussões coletivas com o objetivo de ultrapassar a fragmentação do ensino, por meio da articulação das diferentes áreas do conhecimento, logo, a compreensão da realidade na sua totalidade, a fim de construir a identidade do ser humano como sujeito participativo de sua própria história, torna-se fundamental.

Segundo Moraes e Navas (2010, p. 49), “[...] para fazer com que o ambiente seja um espaço agradável de convivência e de transformação, que favoreça processos do ensino e da aprendizagem, temos que conhecer novas teorias e saber como aplicá-las, no sentido de facilitar a criação de cenários de aprendizagem significativa".

Corrobora com esta reflexão Tardif (2002, p. 128) sobre a importância de uma pedagogia que priorize a "[...] tecnologia da interação humana, colocando em evidência, ao mesmo tempo, a questão das dimensões epistemológicas e éticas", apoiada necessariamente em uma visão de mundo, de homem e sociedade.

Nesse sentido, uma prática pedagógica precisa ter dinâmica própria que lhe permita $\mathrm{O}$ exercício do pensamento reflexivo, conduza a uma visão política de cidadania e que seja capaz de 
integrar a arte, a cultura, os valores, a interação e propiciar, assim, a recuperação da autonomia dos sujeitos e de sua ocupação no mundo, de forma significativa.

Nas palavras de Moraes e Navas (2010, p. 180), “[...] além de aprendiz e inovador permanente, construtor e reconstrutor do conhecimento e de sua própria aprendizagem, um bom docente é aquele capaz de ajudar seus estudantes a desenvolver habilidades e competências consideradas fundamentais a sua sobrevivência e a transcendência".

Portanto, os desafios e as perspectivas na formação docente visando à aprendizagem significativa, por meio, das metodologias ativas e da educação híbrida, impulsionam os professores a reflexões críticas, complexas, colaborativas e contextualizadas no âmbito educacional em uma sociedade pautada nos avanços tecnológicos.

Isso requer leituras e estudos das dimensões que formam a educação na teoria e prática, sendo assim, a formação docente precisa garantir o domínio dos conhecimentos específicos da sua área, mas também saber ensiná-los e compreender o significado e as possibilidades atribuídas aos estudantes para que se apropriem dos conteúdos e façam uso dos conhecimentos para se tornarem sujeitos protagonistas e aptos a superar os desafios e enfrentamentos sociais.

\section{EDUCAÇÃO HÍBRIDA}

Entende-se que a mudança de paradigma gerada pela educação digital, possibilita a construção de comunidades de aprendizagem que envolvam os sujeitos de forma integral e que exija uma presença cognitiva e social que se inter-relacionam. Acredita-se que esta inter-relação ocorra nos momentos nos quais os estudantes constroem significado diante de uma situaçãoproblema, utilizando-se do pensamento complexo e na capacidade de se projetarem de forma social, por meio das interações e da comunicação.

Os estudantes, com acesso constante as tecnologias, e a conexão à internet, podem aprender de diferentes formas, e suas aprendizagens podem ser complementadas por momentos presenciais, nos quais ocorrem as trocas de ideias, a aplicação de conteúdos, a resolução de problemas e atividades colaborativas.

Os ambientes virtuais, quando estruturados com intencionalidade tendem a disponibilizar maior qualidade nas oportunidades de ensino e de aprendizagem qualidade Em seus estudos Carey, (2015, p. 252), cita que "[...] a inovação constante das tecnologias proporciona espaços para que os docentes ofereçam uma educação diferenciada e personalizada", ele alerta que com as possibilidades das inovações tecnológicas e das mudanças mercadológicas também pode acontecer de menos educadores atenderem cada vez mais estudantes.

Entende-se que nos processos de educação a distância, também é possível ter um elevado grau de proximidade afetiva, relacional e comunicacional, sendo assim, nestes processos educacionais destaca-se as possibilidades de presença efetiva, tanto social, como cognitiva e docente, que serão possíveis com recursos tecnológicos efetivos e uma proposta didáticopedagógica-tecnológica de qualidade.

Numa proposta híbrida/semipresencial/blended (termos que se complementam) significa oferecer espaços para que o aprendizado virtual e o presencial aconteçam de forma interconectada e que o conteúdo não seja mais o diferencial.

Entende-se que a estruturação da proposta de educação com tecnologias possa oferecer maior dinamicidade, fluidez, interação, comunicação, além de poder contar com metodologias para aprendizagem ativa, que impulsionam o estudante para um nível cognitivo mais elevado, oferecendo oportunidades de criação, avaliação, e solução de problemas. 
Recursos como as bibliotecas virtuais, conteúdos estruturados em formatos diferenciados como: SCORM, videoaulas, podcasts, animações, storytelling, entre outros, proporcionam diferentes oportunidades de aprendizagens para os estudantes e constituem ferramentas capazes de apoiar propostas educacionais híbridas, despertando o estudante para a construção do conhecimento.

A ideia de flexibilidade que os ambientes online e as propostas híbridas oferecem, não pode ser considerada como falta de estruturação e intencionalidade, pois é fundamental apresentar objetivos bem definidos quanto ao que ensinar, como ensinar e como avaliar.

Em relação as possibilidades educacionais verifica-se em diversos estudos, corroborados por Santos (2018, p. 194) que em muitas propostas a “[...] educação sempre foi 'híbrida”, por estar em espaços diferenciados, por usar metodologias misturadas, por envolver diferentes faixas etárias, por utilizar-se de muitas estratégias didáticas, o que diferencia o momento atual é a presença de tecnologias e inovações, que tornam-se aliadas para a apresentação dos conteúdos, para proporcionar a interação entre estudantes de diferentes espaços, para simulações, realidade imersiva, entre outros recursos já criados e a serem criados ou adaptados para a educação.

A educação híbrida tende a apoiar os estudantes a aprenderem com maior qualidade quando existe a construção de uma proposta diferenciada, com intencionalidade nas atividades online e presencial, com mecanismos de interação, acompanhamento, avaliação e feedback constantes.

O importante é que as instituições levem em consideração as etapas da sequência de aculturação para a implantação de propostas híbridas, iniciando com experiências mais próximas as do ambiente presencial, em um segundo momento inserindo a flexibilidade das atividades com inserções online e na sequência, experiências de aprendizagem diferenciadas mais ativas, mas totalmente interrelacionadas com o que é realizado online.

Percebe-se que a construção de propostas para a educação híbrida tende a envolver diferentes atores para que possa ser instituída com qualidade, além de envolver recursos tecnológicos e profissionais de outras áreas que contribuam no desenvolvimento de materiais e plataformas.

O pesquisado do tema Christensen et al. (2013, p.24) aponta que

A opção é inventar uma solução híbrida que dê aos educadores "o melhor dos dois mundos" - isto é, as vantagens do ensino online combinadas a todos os benefícios da sala de aula tradicional. A opção disruptiva é empregar o ensino online em novos modelos que se afastem da sala de aula tradicional, e foquem inicialmente nos não-consumidores, que valorizem a tecnologia pelo que ela é mais adaptável, acessível e conveniente.

Entende-se ser necessário um tempo de aculturação para a implantação das propostas híbridas, e a seguir apresenta-se o diagrama que resume as características elencadas pela pesquisadora Santos (2018, p. 421), em relação ao processo de educação híbrida, tanto para estudantes, docentes e gestores. 


\section{Figura 1: Características da educação híbrida}

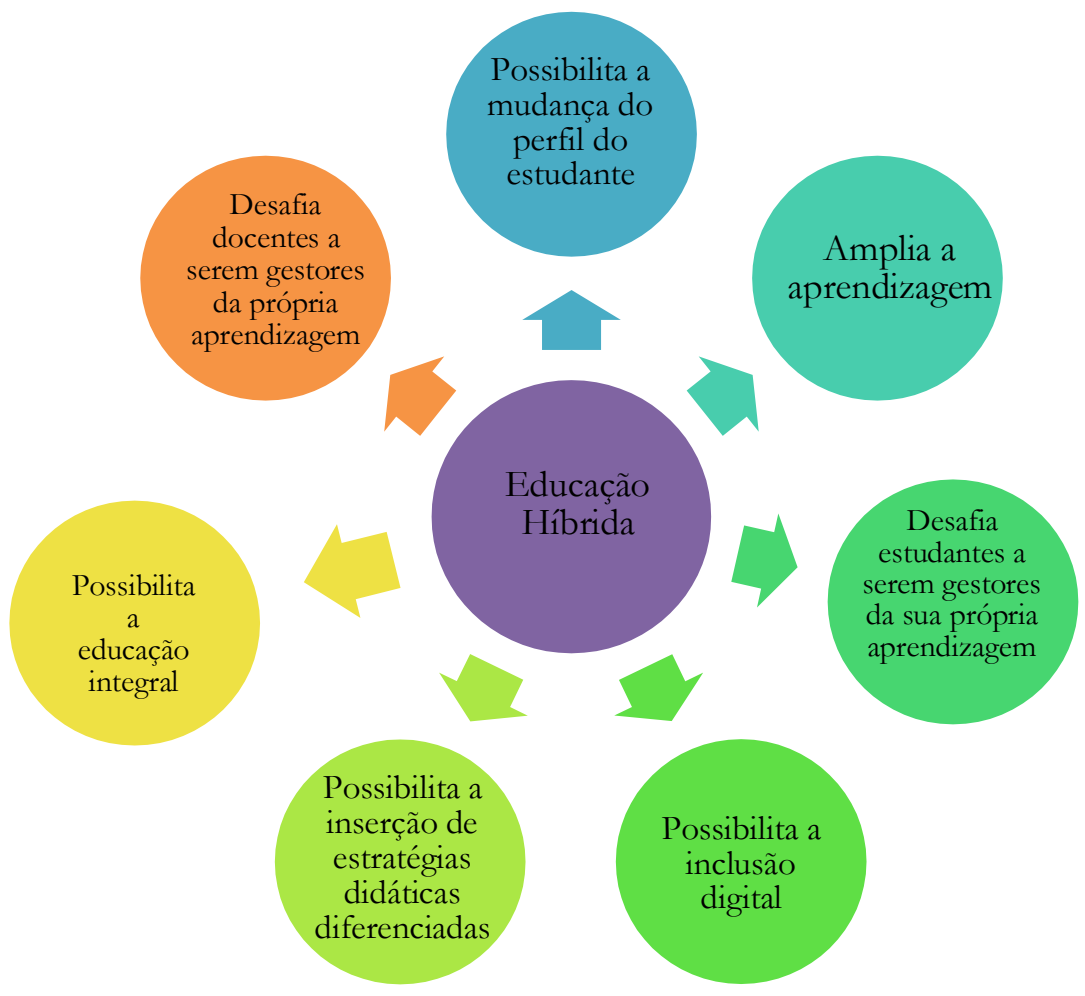

Fonte: Santos (2018, p. 421)

A estrutura das propostas totalmente a distância ou híbridas tendem a oportunizar o desenvolvimento de competências mais amplas como a autonomia, o auto estudo, a gestão do tempo e a comunicação, elementos tão essenciais para a vida neste século e que podem ser um diferencial tanto para a vida pessoal como no mundo do trabalho.

Nas propostas híbridas com uso de tecnologias diferenciadas, pode-se adotar metodologias para aprendizagem ativa proporcionando, ao estudante e aos docentes, processos interativos de conhecimento, momentos de análise, estudo, pesquisa e desenvolvimento de competências essenciais ao século XXI. O uso de estratégias didático-pedagógicas-tecnológicas diferenciadas tende a acontecer nos ambientes presenciais e online, por meio dos processos de mediação e interatividade que ocorrem de múltiplas formas.

Numa perspectiva mais ampla pode-se pensar em propostas educacionais que unam bibliotecas, museus, espaços de empresas como ambientes ricos para aprendizagem, em um contexto diferenciado, pode ocorrer a montagem de infraestrutura física com realidade aumentada e virtual, oferecendo uma aprendizagem imersiva e altamente contextualizada, com propostas de experiências que incluem feedback dos estudantes em tempo real, aliada a sistemas de acompanhamento de docentes e inteligência artificial.

Sugestões apoiadas pelas tecnologias podem proporcionar uma aprendizagem mais efetiva, pois as pessoas estão cada vez mais conectadas e torna-se necessária a mudança de mindset, para que as novas propostas possam ser mais do que o uso da tecnologia na educação como obrigatoriedade ou modismo. Castells (2016) destaca: 
Internamente, os estudantes interagem constantemente entre si e com seus professores, compondo de fato uma comunidade virtual, ao mesmo tempo em que eles também interagem no mundo real, no campus e em sala de aula. Materiais necessários para ensino e pesquisa podem ser acessados online. Atualmente, $97 \%$ da informação no mundo está digitalizada e $80 \%$ está disponível na internet e em outras redes.

Entende-se que tanto as crianças, como os jovens e até os adultos com a inserção das tecnologias nos seus cotidianos, estabelecem uma relação diferenciada com o aprender. Este aprendizado onlife, que acontece em todo tempo e lugar, proporciona um universo para que possa ser desenvolvido nos estudantes, competências relacionadas a produção, criação, inovação e colaboração, pois as práticas sociais no ciberespaço apresentam características mais participativas, colaborativas e de construção coletiva do conhecimento.

\section{PROCIDIMENTOS METODOLÓGICOS}

Esse estudo contou com um questionário estruturado de abordagem qualitativas no objetivo de discutir e refletir sobre a visão do professor autor e desenvolvedor na produção de material didático para educação híbrida na graduação e pós-graduação.

$\mathrm{Na}$ proposta de investigação, que teve embasamento na pesquisa de Santos (2018), além de refletir sobre conceitos da educação híbrida, buscou-se, por meio da realidade do professor levantar informações sobre sua formação docente.

Contextualmente, a escolha da aplicação desta proposta com docentes da graduação e pósgraduação deve-se ao fato de que as Instituições de Ensino Superior vêm adotando uma postura onde a educação digital, por meio de metodologias ativas que utilizam recursos, ferramentas e dispositivos digitais, tem se tornado cada vez mais presentes no âmbito acadêmico.

No contexto específico dessa pesquisa, o questionário estruturado aplicado aos docentes contou com 15 perguntas, sendo 11 perguntas fechadas e 4 (quatro) perguntas abertas. Os oito professores envolvidos na pesquisa produzem material para educação híbrida, sete são mulheres e possuem entre 29 a 44 anos, sendo que $50 \%$ têm de 35 e 36 anos e $87,5 \%$ possuem outra graduação ou pós-graduação completa após a primeira graduação.

Os pontos iniciais questionados foram em relação ao perfil do(a) professor(a), em seguida foi questionado se o docente acredita na proposta de educação híbrida/semipresencial. Todos os professores responderam que acreditam nessa modalidade de ensino, $62,5 \%$ totalmente e 37,5\% parcialmente.

Ao serem questionados se acreditam que os(as) professores autores e desenvolvedores de materiais precisam de formação específica para a produção de conteúdo para educação híbrida/semipresencial, 75\% dos(as) professores(as) afirmaram que concordam com a afirmação, como pode-se observar a seguir: 
Figura 2: Acredita que os(as) professores autores e desenvolvedores de materiais precisam de formação específica para a produção de conteúdo para a educação híbrida/semipresencial

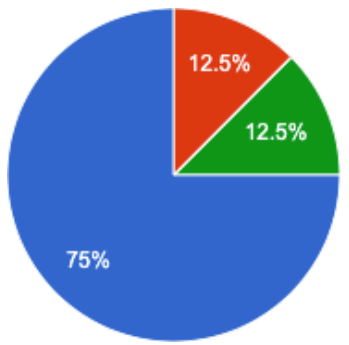

Concordo totalmente

Concordo parcialmente

Năo concordo e nem discordo

- Discordo parcialmente

Discordo totalmente

Fonte: os autores, 2019.

Por outro lado, quando questionado se os docentes acreditam que os(as) professores(as) formadores que dão aula no momento presencial precisam de formação específica para a produção de materiais/conteúdos para a educação híbrida/semipresencial, as respostas se diversificam, como pode-se observar a seguir.

Figura 3: Acredita que os professores formadores que dão aula no momento presencial precisam de formação específica para a produção de materiais/conteúdos para a educação híbrida/semipresencial
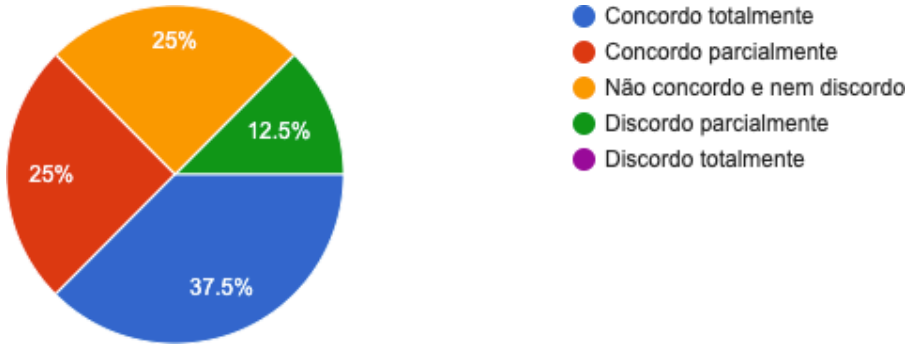

Fonte: os autores, 2019.

Pode-se observar nos dois gráficos apresentados (Figuras 2 e 3) que os próprios docentes acreditam que são necessárias formações específicas para os educadores trabalharem no modelo híbrido, mas que 12,5\% dos docentes pesquisados, acreditam que os(as) professores(as) do momento presencial já possuem conhecimento para a produção de materiais/conteúdos para a educação híbrida/semipresencial. Complementando, 50\% dos docentes acreditam possuir conhecimento necessário para criar propostas utilizando tecnologias, o que corrobora com os dados levantados.

Ao serem questionados para definir em uma palavra a descrição de um bom material para educação híbrida/semipresencial, duas palavras se destacaram por serem mencionadas mais de uma vez: objetividade e contextualização. Isso mostra que os docentes compreendem a importância e as singularidades dos materiais para a educação híbrida/semipresencial.

Outra questão que se destaca na autorreflexão é a proposta dos participantes da pesquisa descreverem em uma palavra como "[...] sua ação na construção dos materiais apoia a qualidade da educação híbrida/semipresencial”. As palavras citadas foram: diferencial, análise, compreensão, engajamento, revisão, adequação, clareza e entendimento global. Percebe-se nas palavras citadas que o docente está comprometido com o material produzido ao ponto de perceber a singularidade e a especificidade da educação híbrida/semipresencial. 
Para finalizar o questionário, os(as) professores(as) foram convidados a registrar um comentário sobre as disciplinas híbridas/semipresenciais. Os comentários complementam a necessidade de formação específica aos docentes e um planejamento diferenciado para essas disciplinas.

Para a construção de uma disciplina no modelo semipresencial é necessário que haja capacitação dos profissionais envolvidos. Os docentes precisam entender que nem sempre o que fazem no presencial dá certo no semipresencial e que a estrutura das aulas será diferente. (Professor 8)

A proposta é inovadora, porém precisa mudar a mentalidade dos professores e alunos que se dispõem a esse tipo de ensino. O momento presencial deve ser mais interativo para que o aluno se motive a continuar estudando sozinho e a instituição proporcionar meios para que essa prática aconteça. (Professor 2)

O planejamento de disciplinas blended é um trabalho em conjunto entre professores e designer educacional, assim não podemos deixar de frisar que a decisão final sobre o que adotar e modificar é do professor que domina o conhecimento da área. Para realizar este trabalho com qualidade existem muitos fatores que influenciam, a compreensão modelo pelo professor é um deles, mas não é o único, posso citar, por exemplo, a dedicação dos professores, a reforma de pensamento para planejar as atividades em um novo formato e o tempo de amadurecimento deste processo. (Professor 4)

Acho que são uma oportunidade para reduzir cada vez mais as aulas expositivas, aproveitando o momento em sala de aula para a prática, a aplicação, o trabalho em equipe, atividades desafiadoras e o feedback imediato, o que coloca os estudantes em ação, consequentemente contribuindo com a aprendizagem. Muitos professores já trabalham desta forma no presencial, nestes casos acredito que o semipresencial seja uma maneira de sistematizar o que acontece na prática. (Professor 6)

É perceptível nos comentários dos(as) professores(as) que eles acreditam na educação híbrida/semipresencial, estão comprometidos na produção de materiais com utilização de recursos digitais diferenciados e que acreditam que a formação docente específica deve acontecer para que o docente produza materiais e conteúdos cada vez mais diferenciados e alinhados com a tecnologia.

Entende-se que o outro ponto importante apresentado na pesquisa foi a importância do planejamento das disciplinas híbridas, o alinhamento entre as equipes responsáveis pelos conteúdos e as tecnologias envolvidas para que os estudantes tenham acesso a educação de qualidade.

Finalizando, pode-se perceber a dedicação e o comprometimento dos professores autores e desenvolvedores na produção de material didático para educação híbrida na graduação e pósgraduação. Fica evidente a importância da formação específica desses docentes para utilização de metodologias ativas com o uso de tecnologias para esse modelo de ensino e o cuidado com o planejamento dessas disciplinas, principalmente para alinhar os momentos presenciais e a distância.

\section{CONSIDERAÇÕES FINAIS}

O artigo mostra que a educação digital, mais especificamente a educação híbrida, é uma modalidade que tende a possibilitar maior sinergia as necessidades atuais da sociedade. Com seus espaços modulares e sua característica flexível e personalizável, a educação híbrida/semipresencial tem ganho espaço nas instituições de Ensino Superior como um impulsionador da graduação e pós-graduação. 
O questionário aplicado contou com quinze perguntas abertas e fechadas que revelaram a visão de professores autores e desenvolvedores na produção de material para educação híbrida. A pesquisa mostra o comprometimento dos docentes com a produção dos materiais, a importância do planejamento das disciplinas considerando os momentos presenciais e a distância.

Entende-se com essa experiência que a educação híbrida/semipresencial é uma realidade e que vem crescendo frente as demandas de professores formados para trabalhar na produção de materiais para educação híbrida. A formação docente específica é essencial para se trabalhar nesta modalidade, principalmente com o uso de tecnologias, pois professores que vem de uma realidade do ensino presencial muitas vezes não estão preparados para os desafios e as diferenças das propostas híbridas.

O olhar referente as possibilidades que a educação digital oferece amplia o escopo de atuação de docentes e estudantes, o que possibilita espaços de aprendizagem diferenciados e a formação ao longo da vida.

\section{REFERÊNCIAS}

ALMEIDA, Elizabeth; VALENTE, José. Integração currículo e tecnologias e a produção de narrativas digitais. Currículo sem Fronteiras, v. 12, n. 3, p. 57-82, set./dez.2012.

BACICH, Lilian; MORAN, Jose. Metodologias ativas para uma educaşão inovadora: uma abordagem teórico-prática. Porto Alegre: Penso, 2018.

CANDAU, Vera M. Ferrão, MOREIRA, Antônio Flávio Barbosa. Indagacõoes sobre currículo: currículo, conhecimento e cultura. Brasília, Distrito Federal: MEC/SEB, 2007.

CAREY, Kevin. The end of college: creating the future of learning and the university of everywhere. New York, New York: Riverhead Books, 2015.

CASTELLS, Manuel. Cada universidade deveria ser livre para inventar. 2016. Disponível em: https://oglobo.globo.com/sociedade/educacao/educacao-360/cada-universidade-deveria-serlivre-para-inventar-diz-manuel-castells-19964451. Acesso em 2 dez. 2017.

CHRISTENSEN, Clayton; HORN, Michael; STAKER, Heather. Ensino híbrido: uma inovação disruptiva? Uma introdução à teoria dos híbridos. 2013. Clayton Christensen Institute. Disponível em https://www.pucpr.br/wp-content/uploads/2017/10/ensino-hibrido uma-inovacaodisruptiva.pdf. Acesso em abr. 2016.

FREIRE, Paulo. Pedagogia da autonomia: saberes necessários à prática educativa. São Paulo: Paz e Terra, 1996.

MONTEIRO, Angélica, MOREIRA, António. O e-learning no ensino superior reflexões em torno de práticas. Centro de Estudos Interdisciplinares do Século XX (CEIS20), Universidade de Coimbra. 2012. Disponível em https://repositorio-aberto.up.pt/bitstream/10216/70504/2/87923.pdf. Acesso em dez. 2017.

MORAES, Maria Cândida, NAVAS, Juan Miguel B. Complexidade e transdisciplinaridade em educação: teoria e prática docente. Rio de Janeiro: Wak, 2010.

MORIN, Edgar. Ciência e consciência. 8. ed. Rio de Janeiro: Bertrand, 2005.

MORIN, Edgar. Os sete saberes necessários à educação do futuro. São Paulo: Cortez; Brasília, Distrito Federal: UNESCO, 2011. 
NÓVOA, António. Vidas de professores. 2. ed., Porto: Porto Ed., 1995. (Coleção Ciências da Educação).

PRETI, Oreste. Educação a distância: fundamentos e políticas. 2. ed. rev. Cuiabá: EdUFMT, 2011.

SANTOS, Katia E. E. A educação híbrida no processo de ensino-aprendizagem: uma proposta norteadora. Tese de Doutorado. Pontifícia Universidade Católica do Paraná, 2018.

SEVERINO, Antônio. Educaşão e transdisciplinaridade: crise e reencantamento da aprendizagem. 1. ed. Rio de Janeiro: Lucerna, 2002.

TARDIF, Maurice. Saberes docentes e formação profissional. Petrópolis, Rio de Janeiro: Vozes, 2002.

Submetido em outubro de 2019. Aprovado em janeiro de 2020.

\section{Informações das autoras}

Katia Ethiénne Esteves dos Santos

Pós-doutoranda em Educação na Pontifícia Universidade Católica do Paraná (PUC-PR)

E-mail:katiaethienne@gmail.com

ORCID: https://orcid.org/0000-0002-6152-9093

Link Lattes: http://lattes.cnpq.br/7680630419858481

Raquel Pasternak Glitz Kowalski

Doutora e Mestre em Educação na PUC-PR, Pós-Graduação em Web Design pela PUC-PR

E-mail: raquel@raqueldesign.com.br

ORCID: https://orcid.org/0000-0002-7394-6505

Link Lattes: http://lattes.cnpq.br/2926131746008333

Sueli Perazzoli Trindade

Doutoranda no Programa de Pós-graduação em Educação na Pontifícia Universidade Católica do Paraná E-mail: sueli.trindade@unoesc.edu.br

ORCID: https://orcid.org/0000-0002-3869-0575

Link Lattes: http://lattes.cnpq.br/2857895918101963 